\title{
Horse and Buggy Crash Study III: \\ Low Illumination and the Sun's Glare in Crashes between Motor Vehicles and Amish / Old Order Mennonite Horse and Buggies
}

\author{
Cory Anderson ${ }^{1}$ \\ Doctoral Candidate in Rural Sociology \\ School of Environment and Natural Resources \\ The Ohio State University
}

\begin{abstract}
The purpose of this study is to identify time periods of particular crash risk through the day for Amish and Old Order Mennonite horse \& buggies. As suggested in prior studies, transitional illumination (dawn/dusk) may be a risk to travel because of a lighting situation that lowers visibility, and the sun's glare at these same times may obstruct motorists' vision. The speed differences between buggies and motor vehicles are already great; reduced vision compounds the problem of response time. To assess risk, I compare horse and buggy traffic counts to the times of horse and buggy crashes over a nine-year period. Periods of particularly high risk include the early morning and early evening, during times of illumination transition and high possibility of glare, though the dusk period is punctuated with an hour of low risk. The afternoon and late evening are periods of modest risk. Mid-morning hours are the lowest risk. This study yields mixed results for the hypothesis. When considered in light of previous findings, this study brings more evidence to bear on illumination and glare as particular risk factors for horse and buggy crashes.
\end{abstract}

\section{Keywords}

Amish; Old Order Mennonite; horse and buggy; illumination; glare; crash

\section{The Horse and Buggy Crash Studies Series}

This article is the third of three by the author addressing horse and buggy crashes. The other two articles are in the same issue, pages 79-99 and 100-115.

\section{Acknowledgements}

I wish to acknowledge an anonymous reviewer for his/her insightful suggestions. 


\section{Introduction}

In the twentieth century, the United States intensified a legislative-based program of cultural, technical, and organizational standardization, including that of ubiquitous infrastructural expansion, health codes, consolidated public schooling, and government welfare (Kollmorgen 1942). Most subcultural enclaves across America (especially in rural areas) assimilated to this centralized homogenization. Several groups, including the Amish, have resisted, consequently facing lengthy showdowns and legal battles on a variety of issues (Place 2003[1993]; Smith 1958; Wittmer 1971).

Among the government's pervasive policies has been their tacit standardization of the motor vehicle as Americans' primary transportation source, accomplished through comparatively low gas prices, Interstate highway construction, removal of trolley and train lines, and the underfunding of mass transportation. As a result, America exceeds all countries in per capita gasoline consumption and automobile ownership. The Amish, however, rejected America's standardization of the personal automobile, instead retaining horse and buggies, mass transportation, “wheeling,” and walking. Legal conflicts between the two systems have resulted. The core philosophical conflict for the American government is the contradiction between modernist progress through macro-standardization and the commitment to protect religious freedom for those desiring a past status quo.

The Amish are one of America's fastest growing populations (Donnermeyer, Anderson, and Cooksey 2013). Where Amish settle, their horse and buggies use roads designed for government standardized high speed travel, making crash causation between automobiles and horse and buggies an increasingly germane topic. While neither the only nor the greatest danger on roads, horse and buggy presence adds additional variables complicating safe travel. ${ }^{2}$ Casespecific legal responsibility for collisions often falls on the motorist, but the public eye is inclined to see the very existence of horse and buggies on the road as the fundamental problem. The government has condoned this mode of transportation, but with some regulations, which often address the buggy’s rear markings (Eicher, Bean, and Buccalo 1997; Garvey 2003; Ives and Brotman 1990). Hence, rear markings have become the sorest point of legal contention (Anderson 2014a; Zook 2003). In only a few cases provision has been made for this mode. ${ }^{3}$

Crashes between horse and buggies and motor vehicles are the second highest cause of sudden injuries among the Amish.(Vitale, et al. 2006) Such crashes tend to produce either very minor injuries to none at all or else very serious / lethal injuries. Around $50 \%$ of crashes result in an injury and around $10 \%$ of buggy crashes involve a fatal injury, a rate at least two to four times higher when an automobile is involved versus just the buggy.(Aaland and Hlaing 2004; Amish Buggy Safety Committee 2000; Piacentini 2003)

While rear markings on the buggy are important, over-attention implies rear markings are seen as a placebo, minimizing other crash causes and locating ultimate responsibility for safety 
with the horse and buggy, not the motor vehicle, road design, laws, or external factors. Researchers are certainly not immune to this trend. ${ }^{4}$ However, a host of factors contribute to crashes, and a proper response should be multifaceted (Amish Buggy Safety Committee 2000). One of the conditions noted as a potential cause for crashes in previous studies is the absence of illumination and the glare of the sun (Anderson 2014b; Dewalt and Bradley 2013). This study focuses specifically on those crashes that may have been affected by illumination and the sun's glare.

\section{Background}

There exist a handful of studies and technical reports about horse and buggy crashes. Several suggest low illumination and the sun's glare may be considerable factors in buggy crashes with automobiles. A study in Lancaster County, PA, the second largest Amish settlement, found that while more crashes occurred during the day than night, the researchers suspected the rate at night was higher (Dempski 1993). Another study used information from an Amish multicommunity newspaper to tally variables at the time of crash, finding that, of those crashes with a time of day reported, evening constituted the majority, though half of all crashed did not indicate a time of day (Dewalt and Bradley 2013).

Anderson (2008; 2014a) conducted an in-depth analysis of 76 horse and buggy crashes in Pennsylvania in 2006 and found half of all crashes were a motor vehicle rear-ending a horse and buggy at mid-block. Two foundational causes account for these crashes. First is the disparity between the horse and buggy's speed and that of the motor vehicle, which gives the motorist less response time than with other motor vehicles. Second is the motorist's failure to see the horse and buggy in enough time to avert a collision. Why the motorist did not visibly notice the buggy when otherwise observing the road may be subcategorized: the buggy was not conspicuous (did not grab the driver's attention), not illuminated, or hidden from view.

Conspicuity has received the bulk of attention, specifically for rear buggy markings. However, Anderson (2008; 2014a) noted the prevalence of several other factors. He noted that nearly half of the rear-end collisions occurred during periods of transitional illumination, and in half of those, the motorist was driving in the direction of sunset or sunrise. Glare would be more appropriately categorized as "hidden from view" than "conspicuity," and low illumination during transitional periods would be an issue "illumination” at a period prior to rear buggy markings responding to headlights but after natural illumination is largely dimmed.

According to the above findings, I hypothesize that the greatest risk of horse and buggy crashes are during transitional periods, the second greatest during night hours, and the least during daylight hours. While this hypothesis is not so bold as to hypothesize glare and transitional illumination cause crashes, it moves in this direction by associating high risk with periods of transitional illumination. 


\section{Methods}

Previous studies only compared the absolute number of crashes during daylight, transitional, and night hours. If there is more buggy traffic during a certain time of day, then, there should be proportionately more accidents compared to periods of less travel. But to determine which period has the greatest risk, the amount of buggy travel during those same times has to be attained

To collect these data, I used methods common in transportation planning. Transportation planners keep records of corridor use rates. The sheer volume of roads means that only minimal data collection can occur for each point. Thus, traffic planners take the average of two strategic traffic counts per location. Both counts occur on a Tuesday, Wednesday, or Thursday, which planners consider normal, representative travel days. The two counts are taken during different times of the year. The data are considered representative of normal travel patterns. On such counts are based the distribution of transportation budgetary allowances and costs for advertising on road signs, for example.

The equipment used by transportation planners to count heavy motor vehicles is ineffective for light-weight buggies. A direct method for collecting horse and buggy data is to be on site and tally buggy traffic. Pursuing this method, I consulted with transportation planners and the local Amish population in Lancaster County, Pennsylvania, to determine a site with a high buggy travel rate. Based on this counsel, I selected an intersection along State Route 340 east of Intercourse and made two all-day counts of horse and buggies that passed by. The counts occurred in the middle of the week, one count in early spring and another in late summer of 2008; the seasonal timing represents a trough and a peak in buggy crashes, respectively, according to aggregate crash data from 1998-2006.

Two assumptions are noted. First, the horse and buggy travel rate at this point is proportionately consistent with rates across Pennsylvania. If ten buggies pass through the intersection in a given hour, then I assume somewhere else, where buggy traffic is only half the rate, five buggies pass through that point. Second, no unusual events or happenings occurred on the days of the samples which would upset normal traffic patterns (I could identify none).

As with other Pennsylvania-based buggy crash studies (Dempski 1993; Ives and Brotman 1990), a PennDOT statewide crash database based on police reports was used. ${ }^{5}$ I extracted all horse and buggy crashes occurring between 1998 and 2006 on Tuesdays, Wednesdays, and Thursdays, aggregating the results into one hour increments. These data are used with the assumptions that nearly all crashes were with Amish or Old Order Mennonite horse and buggies.

\section{Results}

Figure 1 shows the average of the two horse and buggy counts, aggregated into 15 minute increments and reported as a three-period moving average to smooth the trend line. This graph 
visualizes travel patterns through the day. The figure shows that buggy travel slowly increases in the morning, hits a peak in the nine o'clock hour, then descends to a low around the noon hour. Travel increases through the afternoon. It peaks in the four o'clock hour, and then drops off momentarily in the five o'clock hour. Through the six o'clock hour it increases to a 24-hour peak around seven o'clock, at which time it descends to a trough around nine o'clock. The day finishes with a moderate peak around ten o'clock, and by eleven o'clock, horse and buggy traffic has ceased. Many men who work away from home do not use their buggy for commuting. The morning peak rather represents women and elderly running errands or visiting. They return home in the afternoon in preparation for supper, which occurs during the five o'clock trough. Evening visiting and activities occur after supper and most are returning home by the ten o'clock peak.

\section{Figure 1: Horse and buggy Travel Counts (Three-Period Moving Average)}

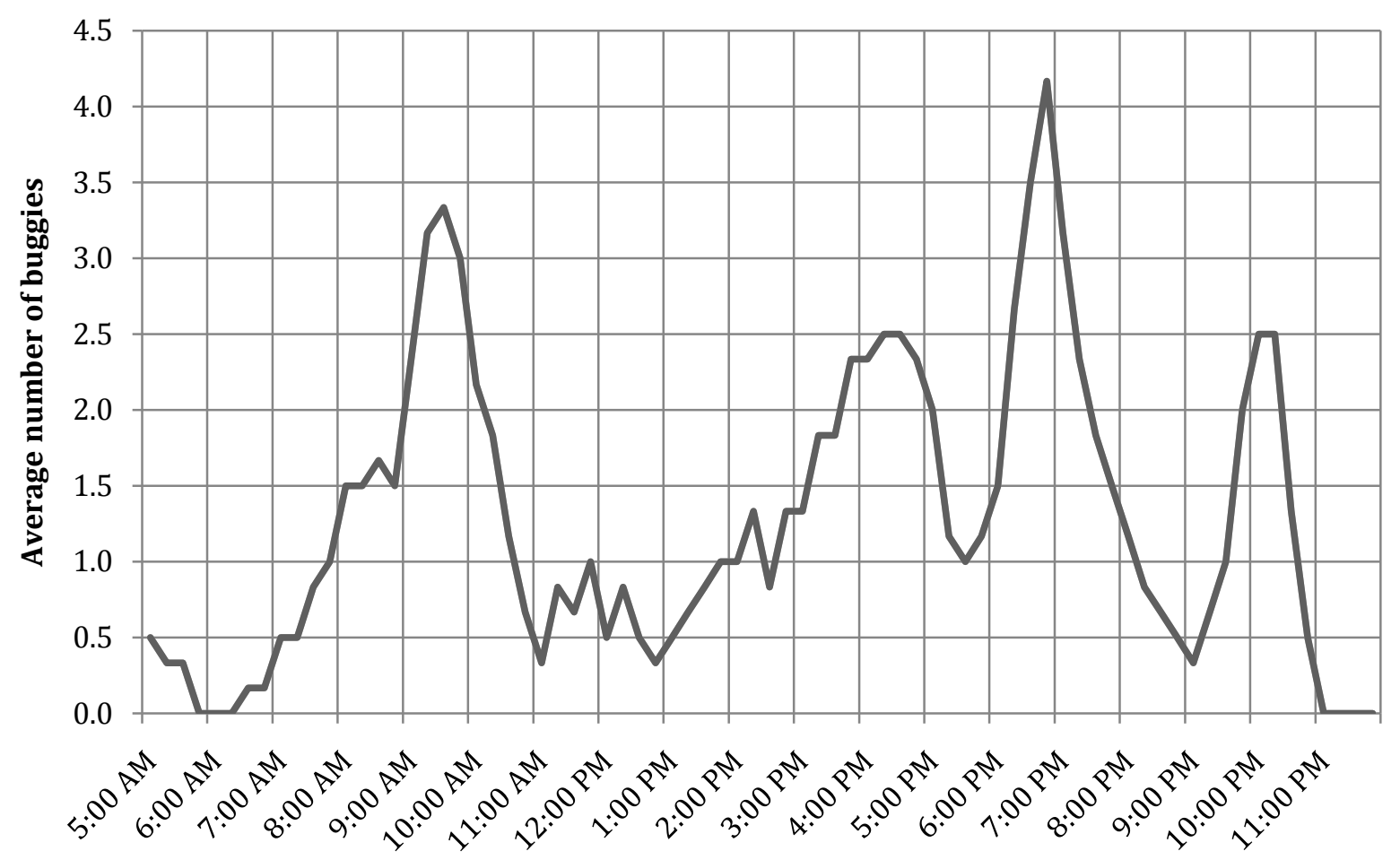

Figure 2 shows the total crashes on Tuesday through Thursday from 1998 to 2006 in one hour increments. Figure 3 calculates a crash risk per hour by dividing the rate of horse and buggy travel (the same data from Figure 1 aggregated into one hour periods) by the rate of all reported crashes from 1998 to 2006 on Tuesdays through Thursdays. Peak crash risk occurs during the two general periods of transitional illumination, dawn and dusk. However, the dusk period also includes a notable trough that complicates the findings. Periods of darkness and periods of full daylight are marked by either low risk or moderate risk. 


\section{Figure 2: Horse and buggy Crash Counts in Pennsylvania, 1998-2006}

\section{(One-Hour Intervals)}

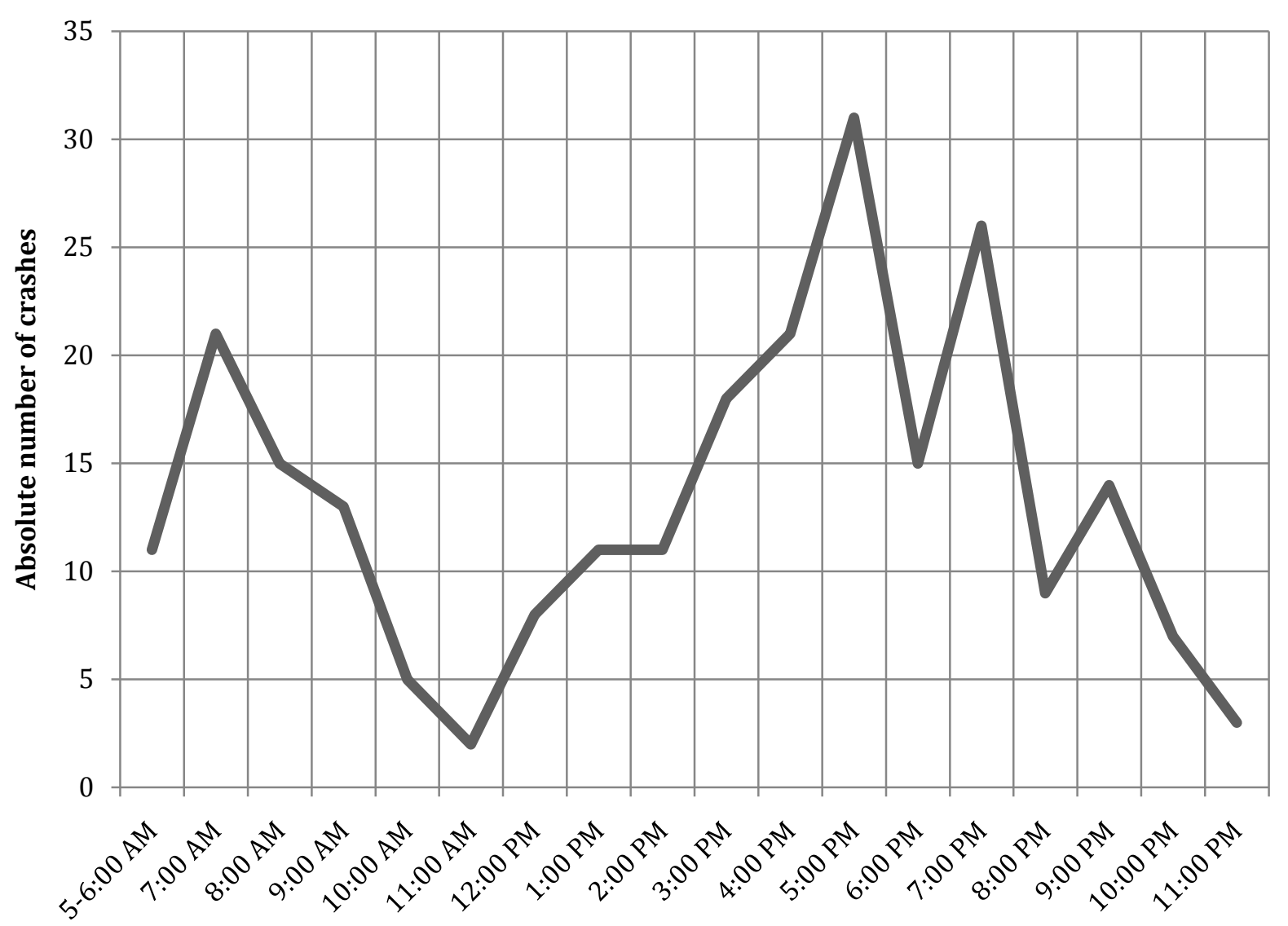

\section{Discussion}

Previous studies suggest transitional illumination periods create greater risk for buggy crashes. Glare may negatively impact a motorist's sight, and indeed, an abnormal number of buggy crashes occur while a motorist is traveling towards the sun (Anderson 2014b). Further, transitional periods provide low natural illumination of the buggy. Yet, it is also not dark enough for the rear reflective markings or L.E.D. lights to be optimally effective (Anderson 2014a).

My hypothesis followed these studies: the greatest risk of crashes (not just absolute crash numbers) is during transitional periods, the second greatest during night hours, and the least during daylight hours. The results partly support the hypothesis. Times during the day that are most representative of nighttime and daylight-late evening and mid-morning and afternoon, respectively-have low to moderate crash risk rates. The two crash risk peaks occur in periods of illumination transition, morning and evening, but the evening also exhibited an hour period of only moderate risk. A generally positive association exists between crash risk and periods of illumination transition, but is not perfect given the five o'clock hour dip in risk. 


\section{Figure 3: Crash Risk by Hour}

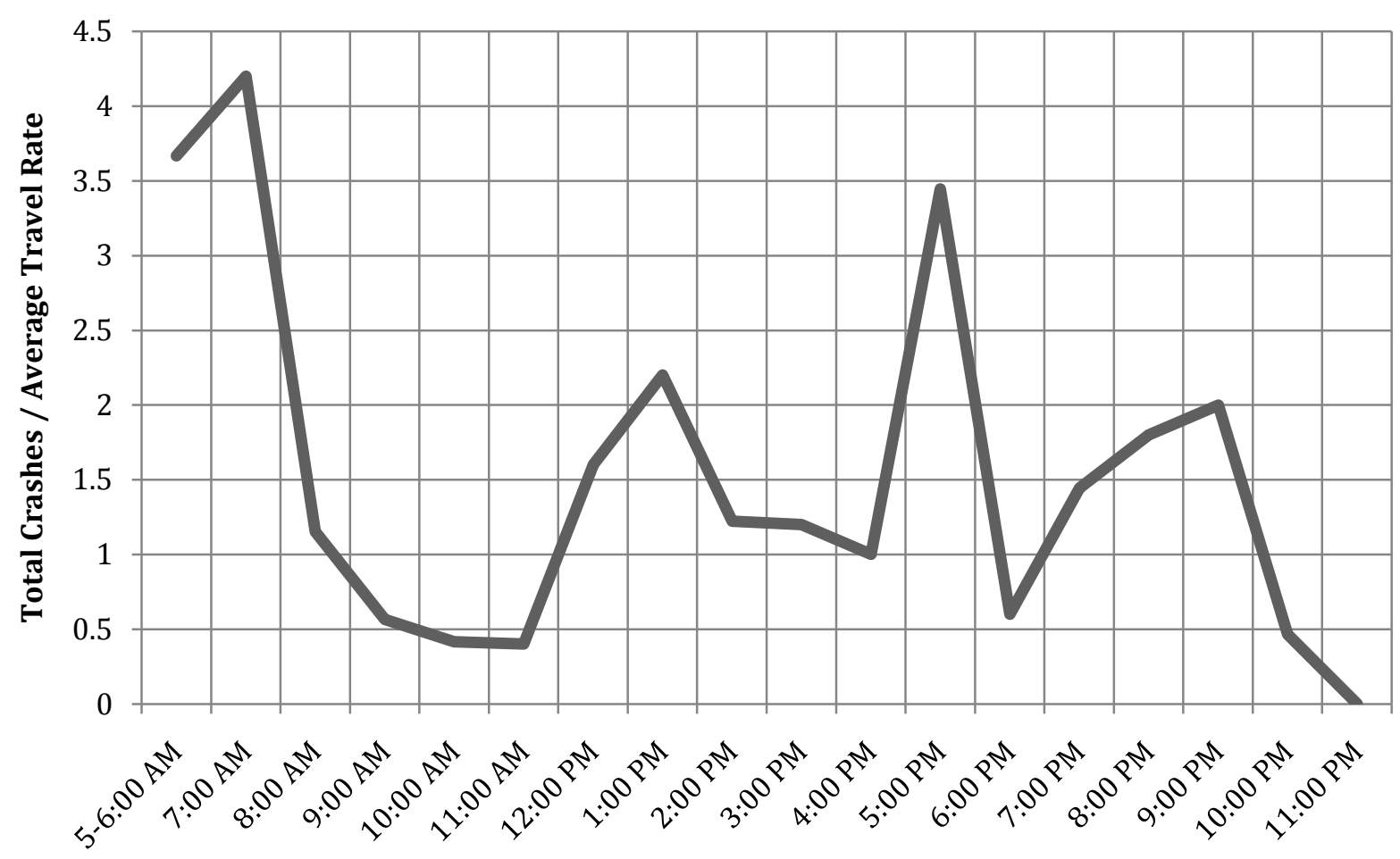

Note: No buggies were observed traveling during the 11p.m. hour; however, three crashes were reported from 19982006 during this time. Thus, risk is calculated as null. No crashes were reported between 12am and 5am; no traffic counts were taken during this period.

The results, when weighed against prior research about motorist and Amish buggy crashes, suggest glare and transitional illumination inflate crash risk for horse and buggies, but other significant variables are unaccounted for that may explain discrepancies, such as the five o'clock dip in risk. Preventative crash measures should not focus on rear markings alone to address rear-end collisions. Motorists should be targeted to increase response time. For example, just as school zones have periods of lower speed limits, certain stretches of road highly traveled by buggies during transitional periods may be marked for a time-specific lower speed limit. Lowering speed limits give motorists more time to react when a horse and buggy is spotted, which will reduce crashes when visibility is limited. Alternatively, adding wider shoulders will remove the horse and buggy from motor vehicle traffic, eliminating the need for a motorist to identify a buggy and respond. Public awareness campaigns, both targeting the Amish and local motorists, may inform them of increased crash risk during this period, urging added precaution.

\section{Endnotes}

${ }^{1}$ Contact information: Cory Anderson, School of Environment and Natural Resources, The Ohio State University, Room 406A, Kottman Hall, 2021 Coffey Road, Columbus, Ohio 43210. cory@beachyam.org 7173301766. 
${ }^{2}$ Or, rather, looking at the problem inversely, the growth of automobiles on highways during the twentieth century has complicated safe travel for horse and buggies, a transport unit using roads prior to automobiles.

${ }^{3}$ An example would be a trail for non-motorized transportation in Holmes County, Ohio, or the reduction of speed limits in Amish and Old Order Mennonite regions in Lancaster County, Pennsylvania.

${ }^{4}$ Though Smith (1958) identified several crash types, he uniformly attributes responsibility to the horse and buggy for one reason or another. Similarly, Ives and Brotman (1990) conclude their analysis of varying crash types by suggesting buggies need more conspicuous rear markings-an oversimplified answer to the various crash causes they noted.

${ }^{5}$ The data used herein was supplied by the Pennsylvania Department of Transportation. The Pennsylvania Department of Transportation specifically disclaims responsibility for any analyses, interpretations, or conclusions drawn in this publication or release.

\section{Words Cited}

Aaland, Mary O., and Thein Hlaing. 2004. “Amish Buggy Injuries in the 21st Century: A Retrospective Review from a Rural Level II Trauma Center.” American Surgeon 70(3):228-34.

Amish Buggy Safety Committee. 2000. Amish Buggy Safety on Ohio's State Roadway System: Analysis and Action Plan. Columbus, OH: Ohio Department of Transportation.

Anderson, Cory. 2008. "Causative Factors of Crashes between a Motor Vehicle and the Amish and Old Order Mennonite Horse and Buggy.” M.A. thesis in Urban and Regional Planning. Richmond, VA: Virginia Commonwealth University.

Anderson, Cory. 2014a. "Horse and Buggy Crash Study II: Overstretching the Slow-Moving Vehicle Emblem's Abilities: Lessons from the Swartzentruber Amish.” Journal of Amish and Plain Anabaptist Studies 2(1):100-115.

Anderson, Cory. 2014b. "Horse and Buggy Crash Study I: Common Crash Scenarios between a Motor Vehicle and the Amish / Old Order Mennonite Horse and Buggy.” Journal of Amish and Plain Anabaptist Studies 2(1):79-99.

Dempski, Anne M. 1993. Non-Motorized Vehicle Study for Lancaster County. Lancaster, PA: Lancaster County Planning Commission. 
Dewalt, Mark W., and Stephanie Bradley. 2013. "Amish Horse Drawn Vehicles and Motor Vehicle Wrecks: An Analysis of Impact and Cause.” Presented at Amish America: Plain Technology in a Cyber World. Elizabethtown College, Elizabethtown, PA.

Donnermeyer, Joseph, Cory Anderson, and Elizabeth Cooksey. 2013. “The Amish Population: County Estimates and Settlement Patterns.” Journal of Amish and Plain Anabaptist Studies 1(1):72-109.

Eicher, Chris, Thomas L. Bean, and Sharyn Buccalo. 1997. “Amish Buggy Highway Safety.” Journal of Multicultural Nursing and Health 3(2):19-24.

Garvey, Philip M. 2003. "Motorist Comprehension of the Slow-Moving Vehicle (SMV) Emblem.” Journal of Agricultural Safety and Health 9(2):159-69.

Ives, W., and S. Brotman. 1990. “A Review of Horse-Drawn Buggy Crashes." Pennsylvania Medicine 93(10):22-24.

Kollmorgen, Walter M. 1942. Culture of a Contemporary Rural Community: The Old Order Amish of Lancaster County, Pennsylvania. Washington, DC: U.S. Department of Agriculture, Bureau of Agricultural Economics.

Piacentini, Anna. 2003. Descriptive Study of Old Order Amish and Old Order Mennonite Buggy Crashes Occurring between 1999 and 2002. Unpublished paper. Elizabethtown, PA: Elizabethtown College.

Place, Elizabeth. 2003[1993]. “Significant Legal Cases.” Pp. 277-87 in The Amish and the State, edited by Donald Kraybill. Baltimore, MD: Johns Hopkins University Press.

Smith, Elmer Lewis. 1958. The Amish People: Seventeenth-Century Tradition in Modern America. New York: Exposition Press.

Vitale, Melissa A., Susan Rzucidlo, Michele L. Shaffer, Gary D. Ceneviva, and Neal J. Thomas. 2006. “The Impact of Pediatric Trauma in the Amish Community.” Journal of Pediatrics 148(3):359-65.

Wittmer, Joe. 1971. “Cultural Violence and Twentieth Century Progress.” Practical Anthropology 18:146-55.

Zook, Lee. 2003. "Slow-Moving Vehicles.” Pp. 145-61 in The Amish and the State, edited by Donald Kraybill. Baltimore, MD: Johns Hopkins University Press. 